\title{
Tea Consumption and Risk of Chronic Obstructive Pulmonary Disease in Middle-Aged and Older Singaporean Adults
}

This article was published in the following Dove Press journal: International Journal of Chronic Obstructive Pulmonary Disease

\author{
Tze Pin $\mathrm{Ng}$ (D) $^{\prime}$ \\ Qi Gao' \\ Xinyi Gwee' \\ Denise QL Chua' \\ Wan $C \operatorname{Tan} \mathbb{1}^{2}$
}

'Gerontology Research Programme, Department of Psychological Medicine, National University of Singapore, Singapore; ${ }^{2}$ Centre for Heart Lung Innovation, Department of Medicine, University of British Columbia,

Vancouver, BC, Canada
Correspondence: Tze Pin Ng

Gerontology Research Programme,

Department of Psychological Medicine,

National University of Singapore, NUHS

Tower Block, $9^{\text {th }}$ Floor, IE Kent Ridge

Road, I 19228, Singapore

Tel $+65-67723478$

Fax +65-67772191

Email pcmngtp@nus.edu.sg
Objective: The anti-oxidant and anti-inflammatory actions of phytochemicals and the smooth muscle relaxant actions of theophylline present in tea may confer pulmonary protection and reduce COPD risk. We investigated tea consumption (black, oolong, or green) association with COPD risks in a population-based cohort study of older adults aged $\geq 55$.

Methods: GOLD criteria was used to identify prevalent and incident cases of COPD (FEV 1 /FVC <0.70) among 4617 participants and 920 participants free of COPD at baseline who were assessed at follow-up 4.5 years later.

Results: Prevalent cases of COPD consumed less tea than their non-COPD counterparts. Estimated odds ratio (OR) and $95 \%$ confidence intervals $(95 \% \mathrm{CI})$ of association with prevalent COPD, adjusted for age, sex, ethnicity, housing type, smoking, alcohol, physical activity and BMI declined across tea consumption levels ( $\mathrm{p}$-trend=0.048), and was lowest for $\geq 3$ cups/day $(\mathrm{OR}=0.77,95 \% \mathrm{CI}=0.61-0.96)$. The cumulated incidence of COPD declined across tea consumption categories $(p$-trend $=0.012)$ and the lowest OR of association $(\mathrm{OR}=0.35,95 \% \mathrm{CI}=0.17-0.69)$ with consuming $\geq 3$ cups/day after co-variate adjustment.

Conclusion: Different kinds of tea showed similar non-significant trends of associations but appeared to be strongest for green tea. Tea consumption in this Asian population was associated with lowered COPD prevalence and incidence.

Keywords: phytochemical, polyphenols, theophylline, epidemiological, longitudinal

\section{Introduction}

Green tea is the most widely consumed beverage in the world, especially in Asia (India, China, Korea, Japan, and South East Asia). The three main types of tea are fully fermented black tea, most widely consumed by $78 \%$ of tea drinkers worldwide, semifermented oolong tea, and non-fermented green tea. Epidemiological studies associate tea with a range of possible health protection against metabolic disorders (type 2 diabetes and dyslipidaemia) ${ }^{1-3}$ and cardiovascular diseases, ${ }^{4-6}$ cancer, ${ }^{7,8}$ neurodegenerative and mood disorders, ${ }^{9,10}$ and increased life expectancy. ${ }^{11}$ In vivo and animal studies support the chemo-preventive, antioxidant, iron-chelating, anti-inflammatory, anti-carcinogenic, glucose and lipid-regulating effects of tea phytochemicals, ${ }^{12-17}$ which include polyphenols such as epigallocatechin gallate (EGCG), epigallocatechin, epicatechin gallate and epicatechin, and their fermentation compounds, such as thearubigins and theaflavins, and many other bioactive constituents, including caffeine, theanine, theobromine and theophylline. 
Chronic obstructive lung disease (COPD) is the third most common cause of death worldwide. ${ }^{18}$ The main risk and protective factors for COPD include smoking, air pollutants, occupational exposure, tuberculosis, ${ }^{19}$ and fruits and vegetables consumption. ${ }^{20,21}$ The anti-oxidant and anti-inflammatory effects of phytochemicals present in fruits and vegetables as well as tea may confer protection against oxidative stress and lung injury from smoking and other noxious causes. Additionally, theophylline (1,3-dimethylxanthine), a drug long used as a potent smooth muscle relaxant in therapeutic doses in COPD and asthma, is naturally present in tea leaves. ${ }^{22,23}$ The amount of theophylline present in brewed tea is significantly less than a therapeutic dose, but it is possible that the continuing long-term consumption of tea theophylline may protect against the risk of COPD. Only one recent cross-sectional study has shown that consuming green tea at least twice a day was associated with a lowered prevalence of COPD in Korea. ${ }^{24}$ No prospective cohort study has yet demonstrated that tea consumption is associated with a lower risk of developing COPD among COPD-free older persons in the population.

In this study, we used cross-sectional and longitudinal data in the Singapore Longitudinal Ageing Study to examine the association of tea consumption of all sorts (black, oolong, or green) with risks of prevalent and incident COPD among community-living older adults aged 55 and older in Singapore.

\section{Materials and Methods Study Design}

The data in this study were derived from combining two population cohorts in the Singapore Longitudinal Ageing Study (SLAS-1 and SLAS-2), an ongoing observational population-based prospective cohort study of ageing and health transition with 3-5 yearly follow-ups among older adults in Singapore. A total of 6074 community-dwelling study participants aged 55 years and above were recruited from different geographical areas in two separate recruitment waves: SLAS-1 recruited 2804 residents in South-East Singapore from 1 September 2003 to 31 December 2004, and SLAS-2 recruited 3270 residents in South-West Singapore, 6 March 2009 and 11 June 2013. Follow-up visits and assessment were conducted 3 to 5 years apart: SLAS-1, March 2005 to September 2007, and November 2007 to December 2009; SLAS-2, January 2013 to August 2018.
Details of the methodology of the SLAS-1 and SLAS-2 cohorts have been described in previous papers. ${ }^{25,26}$ All participants provided informed consent for inclusion before they participated in the study. The study was conducted in accordance with the Declaration of Helsinki, and the protocol was approved by the National University of Singapore Institutional Review Board (NUS-IRB; Reference Code: 04-140). Trained nurses visited the participants at home to perform face-to-face questionnaire interviews and clinical measurements and blood draws were performed in a local study site centre. The extensive range of baseline personal, behavioural and health data included questionnaire and measurement data on respiratory health.

\section{Study Participants}

Among the study participants $(\mathrm{N}=6074)$ in the combined SLAS-1 $(\mathrm{N}=2804)$ and SLAS-2 $(\mathrm{N}=3270)$ cohorts, spirometry was performed in 5017 participants, and 390 participants with technically unacceptable quality spirometry were excluded. Among the remaining 4627 participants, we further excluded 10 participants who did not have baseline tea consumption information. The baseline data of 4617 participants were used for the analysis of prevalent COPD. We conducted a prospective follow-up study on 920 participants who were free of COPD at baseline, and at the first follow up provided technically acceptable quality spirometry data for analysis of incident COPD (Figure 1).

\section{Tea Consumption}

Participants were asked whether they drank tea according to the following frequencies and amount in cups with standard volumes of $250 \mathrm{~mL}$ : (1) never or rarely, or less than one cup in a month, (2) one cup in a month to less than one cup in a week, (3) one cup in a week to less than one cup in a day, (4) one cup in a day to less than 3 cups (5) 3 cups or more in a day, for each of the three main types of tea that were locally consumed: (1) "Western" or "Ceylonese" black tea (from India, Sri Langka or Malaysia, commonly consumed with milk and sugar), (2) Chinese black or oolong tea, and (3) green tea (Chinese, Japanese or Korean). The consumption of any or all types of tea for each individual was aggregated from the summed frequency scores of the individual type of tea and converted to the equivalent categories of consumption frequency. In this study, we combined the two lowest frequencies of tea consumption and analysed the 
SLAS-1

Recruit at baseline $\mathrm{N}=2804$

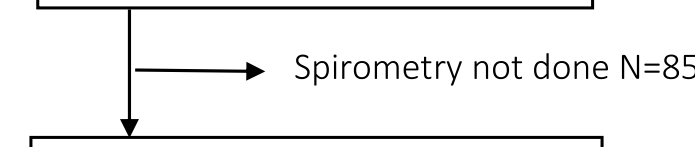

Spirometry done $\mathrm{N}=2719$

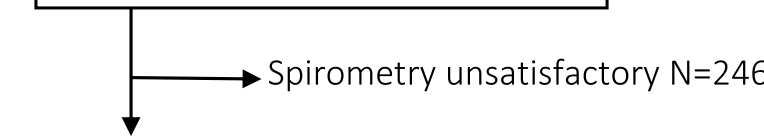

Acceptable spirometry $\mathrm{N}=2473$

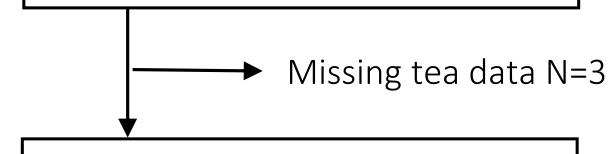

Tea data available $\mathrm{N}=2470$
SLAS-2

Recruit at baseline $\mathrm{N}=3270$

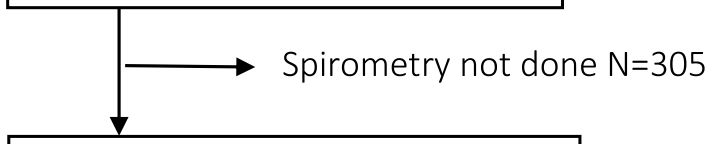

Spirometry done $\mathrm{N}=2965$

Spirometry unsatisfactory $\mathrm{N}=811$

Acceptable spirometry $\mathrm{N}=2154$

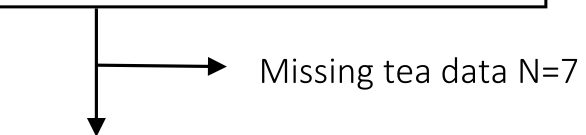

Tea data available $\mathrm{N}=2147$

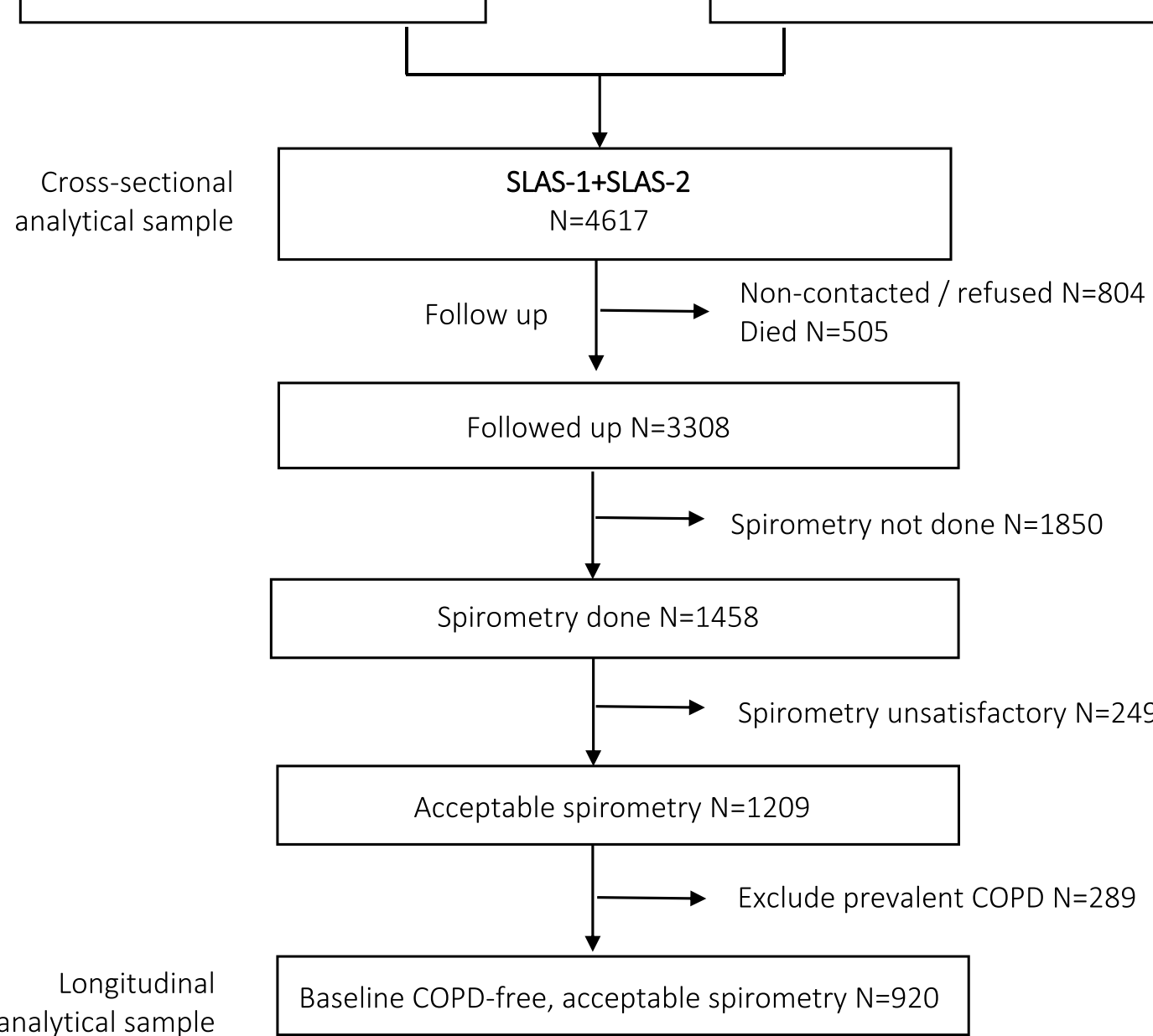

analytical sample

Figure I CONSORT flowchart of study recruitment, baseline assessment, follow-up and data analysis. 
association between four frequency-amount categories of tea consumption and COPD.

\section{COPD}

Pulmonary function tests were performed using a spirometer (the ndd EasyOne ${ }^{\mathrm{TM}}$ Spirometer) that measures flow and volume by ultra-sound transit time, in accordance with the American Thoracic Society standardization of spirometric tests. ${ }^{27}$ The best flow-volume curve from at least 3 attempts and 2 reproducible maneuvers was used. The presence of COPD was defined by a forced expiratory volume in $1 \mathrm{~s}$ (FEV1) divided by forced vital capacity (FVC) of $<0.70$, according to the Global Initiative for Chronic Obstructive Lung Disease classification. ${ }^{28}$ The modified Medical Research Council Questionnaire was used to assess respiratory symptoms of chronic cough and sputum, and breathlessness. ${ }^{29}$

\section{Covariates}

The participants' socioeconomic status was categorized according to their housing status ( $1=$ low end $1-2$ room public housing, $2=3$-room public housing, $3=4-5$ room public housing or private housing type). Smoking exposure was defined by self-reports of smoking history: $0=$ being a never smoker, $1=$ ex-smoker less than 20 cigarettes per day, $2=$ ex-smoker 20 or more cigarettes per day, $3=$ current smoker less than 20 cigarettes per day, or $4=$ current smoker 20 or more cigarettes per day); alcohol exposure by daily alcohol consumption at least one drink ( $1=$ yes, $0=$ no). Physical activity was measured by the summed score of common physical activities of moderate to high intensity performed locally by older people: brisk walking; taiji or qigong; other physical exercises (jogging, gym workouts); active sports (bicycling, swimming, tennis, badminton, bowling, golfing, etc), using a 3-point Likert scale ( $(1=$ less than once a month, $2=$ once a month to less than once a week, $3=$ once a week or more). Body mass index was derived from measurements of weight in kilogram divided by squared of height in metre.

\section{Statistical Analysis}

Group comparison of baseline characteristics was performed with significance testing using chi-squared test for categorical variables and ANOVA test for continuous variables. Logistic regression analysis was used to estimate the odds ratios and $95 \%$ confidence intervals $(95 \%$ CI) of association between tea consumption and prevalent COPD in cross-sectional analysis, and tea consumption and incident COPD in longitudinal analysis, controlling for measured risk factors (age, sex, ethnicity, housing type, smoking, alcohol, physical activity, BMI). The analyses were performed with sufficient sample size using the spirometric definition of COPD, as only a quarter of cases presenting with respiratory symptoms were symptomatic and satisfied the clinical diagnosis of COPD, resulting in small cell sizes by tea consumption categories and inadequate study power.

\section{Results}

Overall, the cohort $(\mathrm{N}=4617)$ mean age was $66.3(\mathrm{SD}=7.7)$ years, and $63 \%$ were females. Tea drinking was prevalent in the majority of the participants, with only $41 \%$ who never or rarely drank tea of any kind. Among tea drinkers, $24.5 \%$ drank $1-2$ cups of tea a day, and $14.3 \%$ drank 3 or more cups a day. The most common kind of tea consumed was Chinese black or oolong tea (40.5\%), followed by Western black tea (37.7\%), while green tea was the least commonly drunk by $19.5 \%$. Tea drinkers and more frequent tea drinkers were more likely to be male, of younger age, living in higher-end housing types, and drank more alcohol. (Supplementary Table S1) There were no significant differences by smoking history or levels of physical activity.

\section{Cross-Sectional Analysis of Prevalent COPD}

Table 1 shows the characteristics of the study participants by the presence and absence of COPD at baseline. Consistent with most reports, participants with COPD were more likely to be of older age, lower socioeconomic status, past or current smokers, reported lower physical activity and had lower BMI. COPD participants compared to non-COPD participants were more likely to be tea drinkers and to drink more of each and all kinds of tea.

The estimated ORs of association with COPD for drinking 3 or more cups of tea of all types in a day, (versus none or rarely) was $0.62(95 \% \mathrm{CI}=0.50,0.77)$ (Table 2). There was a significant monotonic linear trend of association with prevalent COPD across the four tea consumption levels ( $\mathrm{p}$-trend $<0.001)$ : $\mathrm{OR}=0.88(95 \% \mathrm{CI}=0.74,1.05)$ for less than 1 cup a day, and $\mathrm{OR}=0.79(95 \% \mathrm{CI}=0.66,0.93)$ for 1-2 cups a day. In multivariable models that adjusted for age, sex and ethnicity (Model1), and additionally for housing type, smoking, alcohol, physical activity, and BMI 
Table I Baseline Tea Intake and Related Characteristics of SLAS-I and SLAS-2 Study Participants by the Presence and Absence of $\operatorname{COPD}(\mathrm{N}=4617)$

\begin{tabular}{|c|c|c|c|c|c|}
\hline \multirow[b]{2}{*}{ N (\%) of participants } & \multicolumn{2}{|c|}{ No COPD } & \multicolumn{2}{|c|}{ COPD } & \multirow[t]{2}{*}{$\mathbf{p}$} \\
\hline & 3460 & & 1157 & & \\
\hline \multicolumn{6}{|l|}{ Respiratory symptoms } \\
\hline Chronic cough or phlegm & 19.2 & $(666)$ & 23.9 & $(276)$ & $<0.001$ \\
\hline mMRC breathlessness grade I & 9.3 & $(321)$ & 10.8 & (I24) & \\
\hline Grade 2 & 3.7 & $(129)$ & 5.5 & $(63)$ & \\
\hline Grade 3-4 & 0.5 & (18) & 1.0 & (II) & $<0.001$ \\
\hline Symptomatic COPD & NA & NA & 23.9 & $(276)$ & \\
\hline \multicolumn{6}{|l|}{ Tea (all types) intake } \\
\hline None & 39.5 & $(1367)$ & 45.7 & $(529)$ & $<0.001$ \\
\hline$<1$ cup a day & 20.0 & $(693)$ & 20.4 & $(236)$ & \\
\hline $\mathrm{I}-2$ cups a day & 25.1 & $(869)$ & 22.9 & $(265)$ & \\
\hline 3 or more cups a day & 15.3 & $(531)$ & 11.0 & $(127)$ & \\
\hline \multicolumn{6}{|l|}{ Western black tea } \\
\hline None & 60.7 & $(2100)$ & 67.2 & (777) & $<0.001$ \\
\hline$<$ l cup a day & 23.0 & (796) & 19.4 & (224) & \\
\hline $\mathrm{I}-2$ cups a day & 13.4 & $(462)$ & 11.2 & $(130)$ & \\
\hline 3 or more cups a day & 2.9 & $(102)$ & 2.2 & (26) & \\
\hline \multicolumn{6}{|l|}{ Chinese black or oolong tea } \\
\hline None & 58.3 & $(2018)$ & 63.1 & $(730)$ & 0.004 \\
\hline$<$ I cup a day & 26.1 & $(902)$ & 23.5 & $(272)$ & \\
\hline $\mathrm{I}-2$ cups a day & $1 \mathrm{I} .4$ & (393) & 10.3 & $(119)$ & \\
\hline 3 or more cups a day & 4.2 & $(147)$ & 3.1 & (36) & \\
\hline \multicolumn{6}{|l|}{ Green tea } \\
\hline None & 79.2 & $(2740)$ & 84.5 & $(978)$ & $<0.001$ \\
\hline$<1$ cup a day & 15.3 & $(531)$ & 11.3 & $(|3|)$ & \\
\hline $\mathrm{I}-2$ cups a day & 4.2 & $(147)$ & 3.4 & (39) & \\
\hline 3 or more cups a day & 1.2 & $(42)$ & 0.8 & (9) & \\
\hline Sex: Male & 36.8 & $(1274)$ & 37.2 & (430) & 0.834 \\
\hline Female & 63.2 & $(2186)$ & 62.8 & (727) & \\
\hline Age, years & 65.7 & \pm 7.5 & 68.3 & \pm 7.9 & $<0.001$ \\
\hline Ethnicity: Chinese & 94.2 & $(3260)$ & 95.1 & $(1100)$ & 0.548 \\
\hline Malay & 3.4 & $(119)$ & 2.9 & $(34)$ & \\
\hline Indian & 2.3 & $(81)$ & 2.0 & (23) & \\
\hline Housing type: I-2 rooms public & 12.7 & $(439)$ & 19.4 & $(224)$ & \\
\hline 3 rooms public & 24.3 & $(840)$ & 30.3 & $(350)$ & \\
\hline 4-5 room and private housing & 63.0 & $(2|8|)$ & 50.4 & (583) & $<0.001$ \\
\hline Smoking: Never & 82.3 & (2847) & 73.4 & $(849)$ & 0.000 \\
\hline Ex-smoker $<20$ cigarettes per day & 7.3 & $(252)$ & 8.3 & (96) & \\
\hline Ex-smoker $20+$ cigarettes per day & 3.7 & $(128)$ & 4.9 & (57) & \\
\hline Current smoker $<20$ cigarettes per day & 5.4 & $(188)$ & 11.2 & $(130)$ & \\
\hline Current smoker $20+$ cigarettes per day & 1.3 & $(45)$ & 2.2 & $(25)$ & \\
\hline Alcohol daily & 4.3 & $(144)$ & 4.3 & $(50)$ & 0.815 \\
\hline
\end{tabular}

(Continued) 
Table I (Continued).

\begin{tabular}{|c|c|c|c|c|c|}
\hline \multirow[b]{2}{*}{ Physical activity: $<\mid \times$ a month } & \multicolumn{2}{|c|}{ No COPD } & \multicolumn{2}{|c|}{ COPD } & \multirow{4}{*}{$\begin{array}{l}\mathbf{p} \\
<0.001\end{array}$} \\
\hline & 3221 & $(I I \mid 3)$ & 36.0 & $(417)$ & \\
\hline $\mid \mathrm{I} \times$ month to $<\mid \times$ a week & 53.8 & $(1837)$ & 55.2 & (639) & \\
\hline Ix a week or more & 14.0 & $(484)$ & 8.7 & $(101)$ & \\
\hline BMI, $\mathrm{kg} / \mathrm{m}^{2}$ & 23.9 & \pm 3.8 & 23.5 & \pm 3.9 & $<0.001$ \\
\hline
\end{tabular}

Table 2 Cross-Sectional Analysis of Baseline Association of Tea Intake with Prevalent COPD

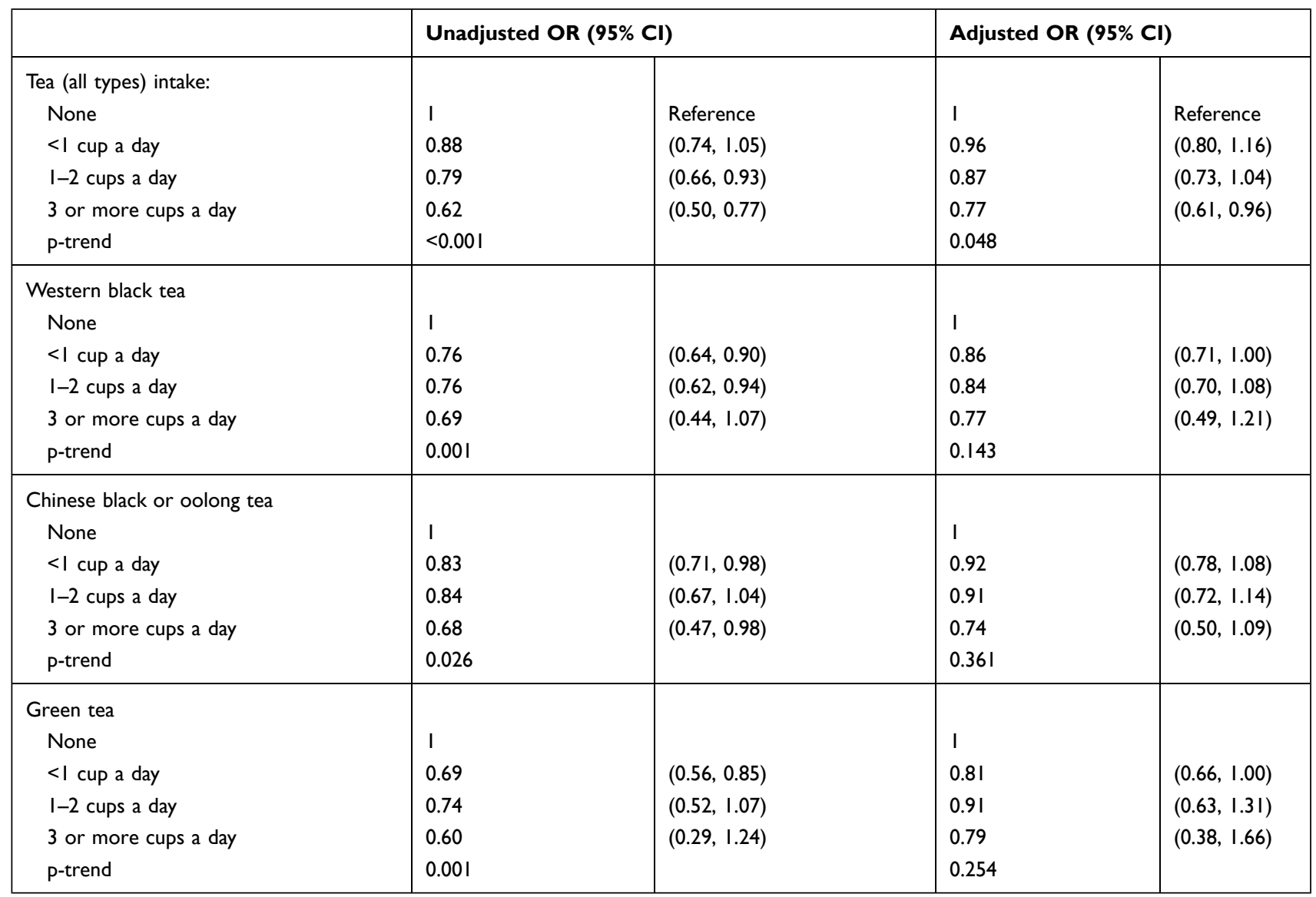

Note: Adjusted for age, sex, ethnicity, housing type, smoking, alcohol, physical activity, BMI.

(Model 2), similar estimates of ORs of association with prevalent COPD for each tea drinking category, and significant linear trend of association across the categories were observed. In the fully adjusted model, the most robust association was observed for drinking 3 or more cups of tea, which alone was significantly associated with prevalent $\mathrm{COPD}(\mathrm{OR}=0.77,95 \% \mathrm{CI}=0.61,0.96)$.

The OR estimates of association with prevalent COPD for different types of tea were similar and significant in the unadjusted model and the model that adjusted for age, sex and ethnicity, but were not significant in the model that adjusted additionally for housing type, smoking, alcohol, physical activity and BMI.

\section{Longitudinal Analysis of Incident COPD}

Among the follow-up participants $(\mathrm{N}=920)$ who were COPD-free at baseline, frequent tea drinkers were more likely to be males, living in higher end housing types, and be smokers (Table 3). The proportion of incident cases of COPD was higher at $19.7 \%$ and $21.8 \%$ among those who consumed no or no more than one cup of tea of all kinds a day, $18.4 \%$ among those who drank 1-2 cups a day, but 
Table 3 Baseline Characteristics of COPD-Free SLAS Participants ( $=920)$ by Tea (All Types) Intake Categories

\begin{tabular}{|c|c|c|c|c|c|c|c|c|c|}
\hline \multirow[b]{2}{*}{$\mathrm{N}$ of participants } & \multicolumn{2}{|c|}{ None } & \multicolumn{2}{|c|}{$<$ I Cup Daily } & \multicolumn{2}{|c|}{ I-2 Cups Daily } & \multicolumn{2}{|c|}{$\geq 3$ Cups Daily } & \\
\hline & & 371 & & 193 & & 220 & & 136 & \\
\hline Sex: Male & 29.9 & $(\mathrm{III})$ & 36.8 & (7I) & 42.7 & (94) & 52.2 & (7I) & $<0.001$ \\
\hline Female & 70.1 & $(260)$ & 63.2 & $(122)$ & 57.3 & (126) & 47.8 & (65) & \\
\hline Age, years & 65.2 & 7.2 & 64.1 & 6.6 & 64.2 & 6.2 & 64.3 & 6.1 & 0.168 \\
\hline Ethnicity: Chinese & 96.2 & (357) & 94.3 & $(182)$ & 94.5 & (208) & 97.8 & (133) & 0.697 \\
\hline Malay & 1.9 & (7) & 2.1 & (4) & 2.1 & (5) & 0.7 & (I) & \\
\hline Indian & 1.9 & (7) & 3.6 & (7) & 3.6 & (7) & 1.5 & (2) & \\
\hline Housing type: $I-2$ rooms public & 11.3 & (42) & 13.0 & (25) & 9.5 & (2I) & 7.4 & $(10)$ & $<0.001$ \\
\hline 3 rooms public & 34.5 & (128) & 24.9 & (48) & 24.1 & (53) & 19.9 & (27) & \\
\hline 4-5 room and private housing & 54.2 & (20I) & 62.2 & $(120)$ & 66.4 & (146) & 72.8 & (99) & \\
\hline Smoking: Never & 86.0 & (319) & 84.5 & $(163)$ & 79.1 & (174) & 77.9 & $(106)$ & 0.032 \\
\hline Ex-smoker $<20$ cigarettes per day & 4.0 & (15) & 7.8 & $(15)$ & 6.4 & (14) & 8.1 & (II) & \\
\hline Ex-smoker $20+$ cigarettes per day & 3.2 & $(12)$ & 3.1 & (6) & 4.5 & $(10)$ & 5.9 & (8) & \\
\hline Current smoker $<20$ cigarettes per day & 5.9 & (22) & 3.1 & (6) & 9.1 & (20) & 6.6 & (9) & \\
\hline Current smoker $20+$ cigarettes per day & 0.8 & (3) & 1.6 & (3) & 0.9 & (2) & 1.5 & (2) & \\
\hline Alcohol daily & 2.2 & $(8)$ & 2.1 & (4) & 2.3 & (5) & 5.9 & (8) & 0.074 \\
\hline Physical activity: < Ix a month & 15.9 & (59) & 14.5 & (28) & 20.9 & (46) & 16.2 & (22) & 0.589 \\
\hline $\mid \mathrm{I} \times$ month to $<\mid \times$ a week & 62.8 & (233) & 62.2 & $(120)$ & 56.8 & $(125)$ & 54.4 & (74) & \\
\hline I $\times$ a week or more & 21.3 & (79) & 23.3 & (45) & 22.3 & (49) & 29.4 & (40) & \\
\hline BMI, $\mathrm{kg} / \mathrm{m}^{2}$ & 23.9 & 3.7 & 23.8 & 3.7 & 24.1 & 3.5 & 23.4 & 2.9 & 0.392 \\
\hline
\end{tabular}

Note: Figures shown are \% $(\mathrm{N})$.

was lowest at $8.1 \%$ among those who drank 3 or more cups a day. (Table 4 and Figure 2) There was a statistically significant linear trend of association with incident COPD across the total tea consumption levels. The estimated OR of association with incident COPD for total tea consumption of 3 or more cups a day, relative to never or rarely, was 0.36 (95\% CI=0.18, 0.70). Adjusted for age, sex, ethnicity, and additionally for all other co-variables, the estimated OR remained unaltered and statistically significant at $0.35(95 \% \mathrm{CI}=0.17,0.69)$.

There were similar magnitudes and trends of OR estimates for different types of tea but they were not statistically significant in the unadjusted model and the multivariable model, except for green tea. In the latter, the OR estimates were statistically significant in the unadjusted model and the model adjusting for age, sex and ethnicity, but not in the full multivariable model.

\section{Discussion}

The observed association of tea consumption with a reduced likelihood of COPD is consistent with the wellknown antioxidant and anti-inflammatory actions of tea extracts from green and black tea. ${ }^{12-15}$ As reactive oxygen species (ROS) scavengers and metal ion chelators, both catechins in green tea and thearubigins and theaflavins in black tea have similarly potent antioxidant properties and may protect against diseases caused by oxidative stress, such as COPD. ${ }^{16,17}$ In vivo, animal studies showed that Chinese green tea ameliorates lung injury in cigarette smoke-exposed rats by lowering the activities of oxidative-stress-related enzymes. ${ }^{30}$ Green tea and catechins are reported to reduce interstitial haemorrhaging, and cellular infiltration and alveolar septal thickness and emphysematous changes in experimentally induced lung inflammation in rodents. ${ }^{31,32}$ Additionally, theophylline is present in tea in small amounts, and is a known bronchodilator in therapeutic use. Theophylline inhibits the enzyme phosphodiesterase, preventing the intracellular break-down of cAMP, with the resulting increase in intracellular cAMP reducing smooth muscle tone and thus dilating the airways. $^{22}$ An increasing body of evidence also suggests that theophylline, at low concentrations, also has antiinflammatory effects related to the activation of histone deacetylases. $^{23}$ 
Table 4 Longitudinal Analysis of Association of Baseline Tea Intake with Incident COPD Among COPD-Free SLAS-2 Participants

\begin{tabular}{|c|c|c|c|c|c|c|}
\hline Tea intake (all types) & \multicolumn{2}{|c|}{ Incident COPD \% (N) } & \multicolumn{2}{|c|}{ Unadjusted OR $(95 \% \mathrm{Cl})$} & \multicolumn{2}{|c|}{ Adjusted OR (95\% Cl) } \\
\hline $\begin{array}{l}\text { None } \\
<1 \text { cup a day } \\
\text { I-2 cups a day } \\
3 \text { or more cups a day } \\
\text { p-trend }\end{array}$ & $\begin{array}{l}19.7 \\
21.8 \\
18.4 \\
8.1 \\
0.009\end{array}$ & $\begin{array}{l}(73) \\
(42) \\
(4 I) \\
(I I)\end{array}$ & $\begin{array}{l}1 \\
1.13 \\
0.93 \\
0.36 \\
0.013\end{array}$ & $\begin{array}{l}\text { Reference } \\
(0.74,1.74) \\
(0.61,1.43) \\
(0.18,0.70)\end{array}$ & $\begin{array}{l}1 \\
1.15 \\
0.95 \\
0.35 \\
0.012\end{array}$ & $\begin{array}{l}\text { Reference } \\
(0.74,1.79) \\
(0.61,1.48) \\
(0.17,0.69)\end{array}$ \\
\hline $\begin{array}{l}\text { Western black tea } \\
\text { None } \\
<\text { I cup a day } \\
\text { I or more cups a day } \\
\text { p-trend }\end{array}$ & $\begin{array}{l}19.0 \\
18.1 \\
14.1 \\
0.261\end{array}$ & $\begin{array}{l}(109) \\
(40) \\
(18)\end{array}$ & $\begin{array}{l}1 \\
0.94 \\
0.72 \\
0.485\end{array}$ & $\begin{array}{l}\text { Reference } \\
(0.63,1.41) \\
(0.42,1.23)\end{array}$ & $\begin{array}{l}1 \\
0.93 \\
0.72 \\
0.516\end{array}$ & $\begin{array}{l}\text { Reference } \\
(0.6 \mathrm{I}, \mathrm{I} .4 \mathrm{I}) \\
(0.4 \mathrm{I}, \mathrm{I} .26)\end{array}$ \\
\hline $\begin{array}{l}\text { Chinese black or oolong tea } \\
\text { None } \\
<\text { I cup a day } \\
\text { I or more cups a day } \\
\text { p-trend }\end{array}$ & $\begin{array}{l}20.0 \\
15.4 \\
16.0 \\
0.143\end{array}$ & $\begin{array}{l}(107) \\
(36) \\
(24)\end{array}$ & $\begin{array}{l}I \\
0.73 \\
0.76 \\
0.24 I\end{array}$ & $\begin{array}{l}\text { Reference } \\
(0.48,1.10) \\
(0.47,1.24)\end{array}$ & $\begin{array}{l}1 \\
0.70 \\
0.75 \\
0.206\end{array}$ & $\begin{array}{l}\text { Reference } \\
(0.46,1.08) \\
(0.45,1.25)\end{array}$ \\
\hline $\begin{array}{l}\text { Green tea } \\
\text { None } \\
<\text { I cup a day } \\
\text { I or more cups a day } \\
\text { p-trend }\end{array}$ & $\begin{array}{l}19.9 \\
13.3 \\
8.9 \\
0.009\end{array}$ & $\begin{array}{l}(142) \\
(20) \\
(5)\end{array}$ & $\begin{array}{l}1 \\
0.62 \\
0.39 \\
0.034\end{array}$ & $\begin{array}{l}\text { Reference } \\
(0.37,1.03) \\
(0.15,1.00)\end{array}$ & $\begin{array}{l}1 \\
0.64 \\
0.42 \\
0.065\end{array}$ & $\begin{array}{l}\text { Reference } \\
(0.38,1.08) \\
(0.16,1.10)\end{array}$ \\
\hline
\end{tabular}

Note: Adjusted for age, sex, ethnicity, housing type, smoking, alcohol, physical activity, BMI.

A recent population-based cross-sectional study from Korea showed a reduced odds of association with prevalent COPD for drinking green tea 2 or more times a day. ${ }^{24}$ In this study, we also show in cross-sectional analysis that tea consumption at 3 cups or more a day was associated with a decreased prevalence of COPD. As well, we show that in a prospective follow-up of participants free of COPD at baseline who were reassessed after 5 years, tea drinking of all types was associated with a decreased cumulative risk of incident COPD. Differences in the measures of tea consumption in the two studies should be noted. The Korean study measured only green tea consumption by frequency, not by the amount. In this study, we measured both the types and amount in cups of tea. As prevalent cases of COPD tend to reflect lesser severity of the disease, these results taken together suggest that tea consumption may have the protective effect of reducing the risk and severity of COPD. Both studies are in reasonable agreement in suggesting that a protective threshold against COPD of green tea consumption could be $1-2$ cups a day.

Based on our data, drinking all kinds of tea as a whole, including black and oolong tea was associated with decreased likelihood of COPD. This suggests that the pulmonary protective effect of tea consumption was not limited to particular types of tea. Although the amount of catechins in black tea is generally lower compared with green tea, ${ }^{15,16}$ the free radical-scavenging activity of black or oolong tea is not significantly impaired, as theaflavins in black or oolong tea possess equally strong antioxidant actions as catechins in green tea. There are heterogeneous groups of tea drinkers among Asians in Singapore, including those who drink mixed types of tea; for example, most green tea consumers also drink black or oolong tea, and for a proportion of tea-drinkers, milk and sugar are added to infusions of black tea ("Western" style tea drinking), including more recent concoction trend of "bubble" tea. We, therefore, distinguish black tea drinking by whether milk (sweetened or unsweetened) is added to the tea infusion (but not specifically for "bubble" tea), because there is some conflicting evidence which suggest that the addition of milk may reduce the anti-oxidant activity of tea, due to the interactions between tea polyphenols and milk proteins, such as between catechins and caseins, among other factors. ${ }^{33,34}$ So far, only the two mentioned studies of Asian populations in Korea and Singapore have shown the 

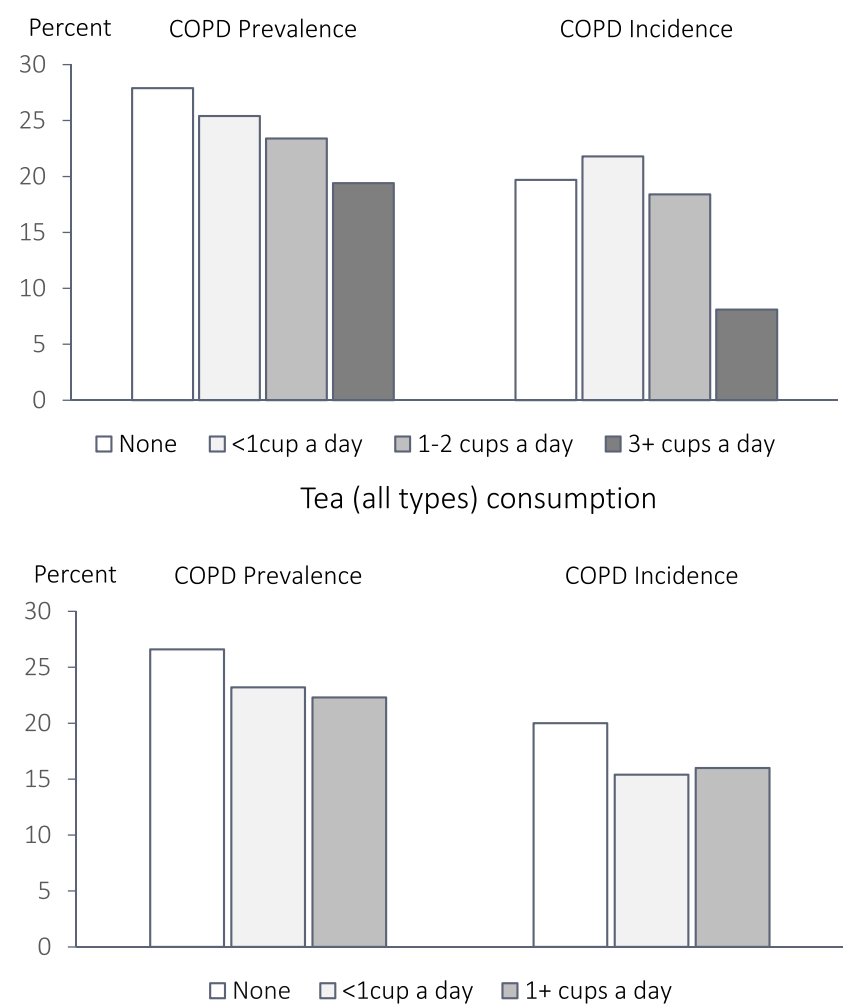

Chinese Black or Oolong Tea consumption

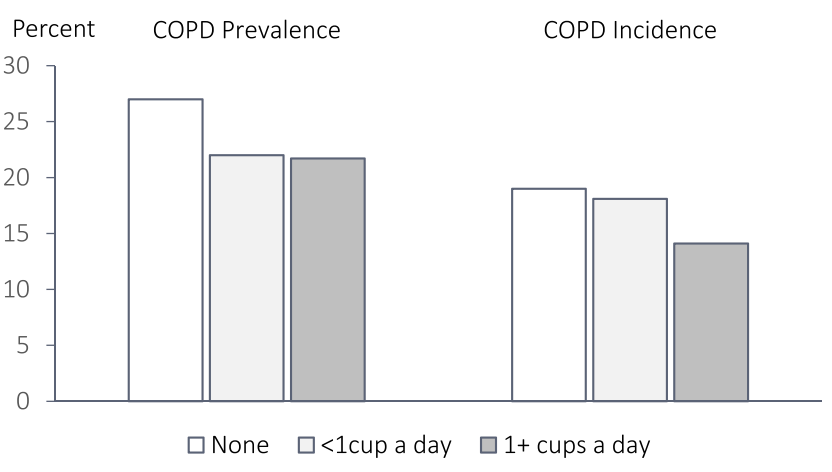

Western Black Tea consumption

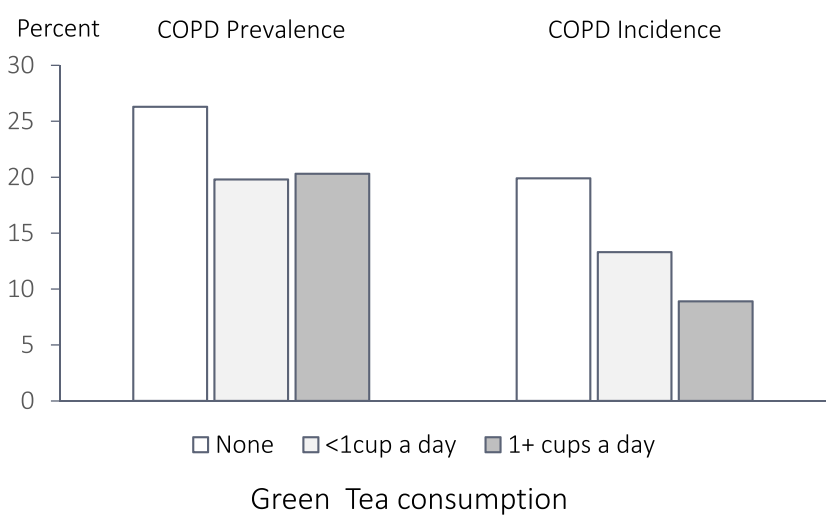

Figure 2 Baseline prevalence and 5-year cumulative incidence of COPD by consumption levels for all and different types of tea. Legends. Western black tea refers to tea consumed with milk and sugar. Chinese tea includes both black, oolong and green tea. Consumption levels are in 3 categories (third category: $\geq 1$ cup/day) for specific tea types, and in 4 fours categories for all tea types (third category further divided into I-2 cups/day and $\geq 3$ cups/day).

link between tea drinking and COPD risk and severity. This may limit the generalization of the findings to only certain Asian populations, such as Chinese, Japanese and Koreans, with sizeable homogeneous groups with pure tea drinking habits that are not mixed with other ingredients such as milk or sugar. More studies are needed especially in Western populations, in which tea drinking with milk and sugar are more common.

There are strengths and limitations in this study. Recall inaccuracies in reporting the types, frequencies and amount of tea consumed by the respondents may limit the study's sensitivity in detecting a true effect. For example, it may be difficult for some responders to differentiate oolong tea from green tea. The accuracy of respondent's subjective self-report of the numbers of cups of tea consumed may also be limited and result in misclassification errors. Such misclassification errors may bias the estimates of effect sizes associated with tea drinking categories towards the null effect. There were adequate sample sizes in the highest consumption level of 3 cups in a day for overall tea consumption combining all three kinds of tea, making for more reliable estimates of effect size. However, for the individual categories of black, oolong and green tea consumption at 3 or more cups a day, the sample sizes were small, hence the highest consumption level categories could only be analyzed for 1 or more cups a day. The protective effect of tea drinking with COPD risk may hence be under-estimated, but despite this, the association with specifically green tea drinking was highly suggestive.

In this population study, COPD was determined spirometrically and included both asymptomatic and symptomatic cases. Approximately a quarter were symptomatic cases of COPD with chronic respiratory symptoms, the latter being typically the sort of cases diagnosed in clinics. It is widely known that the great majority of COPD cases in the community are unrecognized and undiagnosed, and even symptomatic cases of COPD identified in population surveys such as ours are in the majority undiagnosed in the clinics. This should be noted in considering the clinical and public health ramifications of the findings in this study. It is reasonable to suggest that tea drinking could a contributing protective factor that prevents or delays the 
onset or reduces the severity of COPD in the community. Its effect in patients with clinical COPD is expectedly modest; however, further studies may investigate whether the tea consumption in conjunction with pharmacotherapy may help to stabilize COPD while avoiding the need for stepped-up bronchodilator drugs therapy.

Possible selection bias from incomplete sampling of the COPD-free cohort members for follow-up assessment of incident COPD outcome should be considered. We compared COPD-free participants who were re-assessed for incident COPD to those who were not re-assessed, and found that they did not differ by age, sex, housing type, smoking, or tea drinking levels, but were significantly less likely to be of Malay ethnicity and daily alcohol drinkers, and to have higher levels of physical activity. The likely bias from the very small proportion of those who were Malay and daily alcohol drinker can be considered to be trivial; the differences in physical activity level may possibly result in underestimation of incident COPD risks overall in the followed up cohort, but whether this bias is likely to be differential by tea drinking categories is unclear.

In summary, we observed in a cohort of Asian middleaged and older persons that tea drinking was associated with lower prevalence and incidence of COPD. Further studies in other populations with significant tea drinking habits should be conducted to confirm the pulmonary protective effects of tea consumption observed in this study.

\section{Acknowledgment}

We thank the following voluntary welfare organizations for their support: Geylang East Home for the Aged, Presbyterian Community Services, St Luke's Eldercare Services, Thye Hua Kwan Moral Society (Moral Neighbourhood Links), Yuhua Neighbourhood Link, Henderson Senior Citizens' Home, NTUC Eldercare Co-op Ltd, Thong Kheng Seniors Activity Centre (Queenstown Centre) and Redhill Moral Seniors Activity Centre.

\section{Author Contributions}

TPN, QG, XG, DQLC and WCT contributed to the conceptualization, design, conduct and data acquisition of the study; TPN reviewed the literature, analyzed the data, drafted and revised the manuscript; all authors contributed to the interpretation of the results and in the critical review of the manuscript for important intellectual content, and approved the final versions before agreeing to submit the article to the journal, and agreed to take responsibility and be accountable for the contents of the article.

\section{Funding}

The study was supported by research grants from the Agency for Science Technology and Research (A*STAR) Biomedical Research Council (BMRC/08/1/21/19/567) and the National Medical Research Council (NMRC/ 1108/2007; NMRC/CIRG/1409/2014).

\section{Disclosure}

Dr Wan C Tan reports grants from Canadian Respiratory Research Network, outside the submitted work. The authors report no other conflicts of interest in this work.

\section{References}

1. Zheng XX, Xu YL, Li SH, et al. Green tea intake lowers fasting serum total and LDL cholesterol in adults: a meta-analysis of 14 randomized controlled trials. Am J Clin Nutr. 2011;94(2):601-610. doi:10.3945/ajen.110.010926

2. Liu K, Zhou R, Wang B, et al. Effect of green tea on glucose control and insulin sensitivity: a meta-analysis of 17 randomized controlled trials. Am $J$ Clin Nutr. 2013;98(2):340-348. doi:10.3945/ ajcn.112.052746

3. Bahorun T, Luximon-Ramma A, Neergheen-Bhujun VS, et al. The effect of black tea on risk factors of cardiovascular disease in a normal population. Prev Med. 2012;54:S98-102. doi:10.1016/j. ypmed.2011.12.009

4. Zhang C, Qin Y, Wei X, et al. Tea consumption and risk of cardiovascular outcomes and total mortality: a systematic review and meta-analysis of prospective observational studies. Eur J Epidemiol. 2015;30(2):103-113. doi:10.1007/s10654-014-9960-x

5. Arab L, Liu W, Elashoff D. Green and black tea consumption and risk of stroke: a meta-analysis. Stroke. 2009;40(5):1786-1792. doi:10.1161/STROKEAHA.108.538470

6. Kuriyama S, Shimazu T, Ohmori K, et al. Green tea consumption and mortality due to cardiovascular disease, cancer, and all causes in Japan: the Ohsaki study. JAMA. 2006;296(10):1255-1265. doi:10.1001/jama.296.10.1255

7. Sun CL, Yuan JM, Koh WP, Yu MC. Green tea, black tea and breast cancer risk: a meta-analysis of epidemiological studies. Carcinogenesis. 2006;27(7):1310-1315. doi:10.1093/carcin/bgi276

8. Tang N, Wu Y, Zhou B, et al. Green tea, black tea consumption and risk of lung cancer: a meta-analysis. Lung Cancer. 2009;65 (3):274-283. doi:10.1016/j.lungcan.2008.12.002

9. Dong X, Yang C, Cao S, et al. Tea consumption and the risk of depression: a meta-analysis of observational studies. Aust $N$ Z J Psychiatry. 2015;49(4):334-345. doi:10.1177/0004867414567759

10. Ng TP, Feng L, Niti M, et al. Tea consumption and cognitive impairment and decline in older Chinese adults. Am J Clin Nutr. 2008;88 (1):224-231. doi:10.1093/ajcn/88.1.224

11. Ruan R, Feng L, Li J, et al. Tea consumption and mortality in the oldest-old Chinese. J Am Geriatr Soc. 2013;61(11):1937-1942. doi:10.1111/jgs. 12498

12. Chen ML. Tea and health - an overview. In: Zhen CZY, Zhen Y, Cheng S, Chen M, editors. Tea: Bioactivity and Therapeutic Potential. London: Taylor and Francis; 2002:1-16.

13. Rietveld A, Wiseman S. Antioxidant effects of tea: evidence from human clinical trials. $J$ Nutr. 2003;133(10):3285S-3292S. doi: $10.1093 / \mathrm{jn} / 133.10 .3285 \mathrm{~S}$

14. Crespy V, Williamson G. A review of the health effects of green tea catechins in in vivo animal models. $J$ Nutr. 2004;134(12):3431S3440S. doi:10.1093/jn/134.12.3431S 
15. Henning SM, Niu Y, Lee NH, et al. Bioavailability and antioxidant activity of tea flavanols after consumption of green tea, black tea, or a green tea extract supplement. Am J Clin Nutr. 2004;80 (6):1558-1564. doi:10.1093/ajen/80.6.1558

16. Luczaj W, Skrzydlewska E. Antioxidative properties of black tea. Prev Med. 2005;40(6):910-918. doi:10.1016/j.ypmed.2004.10.014

17. Leung LK, Su Y, Chen R, et al. Theaflavins in black tea and catechins in green tea are equally effective antioxidants. $J$ Nutr. 2001;131 (9):2248-2251. doi:10.1093/jn/131.9.2248

18. Lozano R, Naghavi M, Foreman K, et al. Global and regional mortality from 235 causes of death for 20 age groups in 1990 and 2010 : a systematic analysis for the Global Burden of Disease Study 2010. Lancet. 2012;380(9859):2095-2128. doi:10.1016/S0140-6736(12) 61728-0

19. Salvi SS, Barnes PJ. Chronic obstructive pulmonary disease in nonsmokers. Lancet. 2009;374(9691):733-743. doi:10.1016/S01406736(09)61303-9

20. Kaluza J, Harris HR, Linden A, Wolk A. Long-term consumption of fruits and vegetables and risk of chronic obstructive pulmonary disease: a prospective cohort study of women. Int J Epidemiol. 2018;47 (6):1897-1909. doi:10.1093/ije/dyy178

21. Meteran H, Thomsen SF, Miller MR, et al. Self-reported intake of fruit and vegetables and risk of chronic obstructive pulmonary disease: a nation-wide twin study. Respir Med. 2018;144:16-21. doi:10.1016/j.rmed.2018.09.013

22. Gallelli L, Falcone D, Cannataro R, et al. Theophylline action on primary human bronchial epithelial cells under proinflammatory stimuli and steroidal drugs: a therapeutic rationale approach. Drug Des Devel Ther. 2017;11:265-272. doi:10.2147/DDDT. S118485

23. Hussein A, Al-Wadei N, Takahashi T, Schuller HM. Theophylline stimulates camp-mediated signaling associated with growth regulation in human cells from pulmonary adenocarcinoma and small airway epithelia. Int J Oncol. 2005;27(1):155-160.

24. Oh CM, Oh IH, Choe BK, et al. Consuming green tea at least twice each day is associated with reduced odds of chronic obstructive lung disease in middle-aged and older Korean Adults. J Nutr. 2018;148 (1):70-76. doi:10.1093/jn/nxx016
25. Niti M, Yap KB, Kua EH, et al. Physical, social and productive leisure activities, cognitive decline and interaction with APOE-epsilon4 genotype in Chinese older adults. Int Psychogeriatr. 2008;11:1-15.

26. Wei K, Nyunt MSZ, Gao Q, Wee SL, Ng TP. Frailty and malnutrition: related and distinct syndrome prevalence and association among community-dwelling older adults: Singapore longitudinal ageing studies. J Am Med Dir Assoc. 2017;18(12):1019-1028. doi:10.1016/j. jamda.2017.06.017

27. Graham BL, Steenbruggen I, Miller MR, et al. Standardization of Spirometry 2019 Update. An Official American Thoracic Society and European Respiratory Society Technical Statement. Am J Respir Crit Care Med. 2019;200(8):e70-e88. doi:10.1164/rccm.201908-1590ST

28. Vestbo J, Hurd SS, Agustí AG, et al. Global strategy for the diagnosis, management, and prevention of chronic obstructive pulmonary disease: GOLD executive summary. Am J Respir Crit Care Med. 2013;187(4):347-365. doi:10.1164/rccm.201204-0596PP

29. Bestall JC, Paul EA, Garrod R, et al. Usefulness of the Medical Research Council (MRC) dyspnoea scale as a measure of disability in patients with chronic obstructive pulmonary disease. Thorax. 1999;54(7):581-586. doi:10.1136/thx.54.7.581

30. Chan KH, Ho SP, Yeung SC, et al. Chinese green tea ameliorates lung injury in cigarette smoke-exposed rats. Respir Med. 2009;103 (11):1746-1754. doi:10.1016/j.rmed.2009.04.027

31. Di Paola R, Mazzon E, Muià $\mathrm{C}$, et al. Green tea polyphenol extract attenuates lung injury in experimental model of carrageenan-induced pleurisy in mice. Respir Res. 2005;6(1):66. doi:10.1186/1465-9921-6-66

32. Uzun FG, Demir F, Kalender S, et al. Protective effect of catechin and quercetin on chlorpyrifos-induced lung toxicity in male rats. Food Chem Toxicol. 2010;48(6):1714-1720. doi:10.1016/j.fct.2010.03.051

33. Rashidinejad A, Birch EJ, Sun-Waterhouse D, Everett DW. Addition of milk to tea infusions: helpful or harmful? Evidence from in vitro and in vivo studies on antioxidant properties. Crit Rev Food Sci Nutr. 2017;57(15):3188-3196. doi:10.1080/10408398.2015.1099515

34. Ryan L, Petit S. Addition of whole, semiskimmed, and skimmed bovine milk reduces the total antioxidant capacity of black tea. Nutr Res. 2010;30(1):14-20. doi:10.1016/j.nutres.2009.11.005

\section{Publish your work in this journal}

The International Journal of COPD is an international, peer-reviewed journal of therapeutics and pharmacology focusing on concise rapid reporting of clinical studies and reviews in COPD. Special focus is given to the pathophysiological processes underlying the disease, intervention programs, patient focused education, and self management protocols. This journal is indexed on PubMed Central, MedLine and CAS. The manuscript management system is completely online and includes a very quick and fair peer-review system, which is all easy to use. Visit http://www.dovepress.com/testimonials.php to read real quotes from published authors. 